\title{
ÉTICA, HONESTIDADE E INTEGRIDADE
}

Ainda que, desde a exposição de motivos da Declaração dos Direitos do Homem e do Cidadão, de 1789, já havia o reconhecimento de que "a ignorância, o esquecimento e o desprezo aos direitos do homem são as únicas causas dos males públicos e da corrupção dos governos", ao longo das últimas décadas, tem-se tomado consciência de que a corrupção, além de lesionar bens jurídicos fundamentais, desgasta gravemente a ética pública, produzindo a erosão do sistema social e do Estado Democrático de Direito.

Essas referências nos levam a destacar a relevância dos valores e da integridade na construção de uma sociedade digna de ser vivida; em definitivo, nos leva a explorar o problema existente na intrincada relação entre ética e corrupção. Não há como deixar de ressaltar o embate atual para elevar o patamar da decência pública no Brasil, diante da impressionante quantidade de casos e operações que cotidianamente descortinam uma séria intoxicação do Estado pelo vício da vantagem indevida.

Desde a década de 1950-1960, a ética tornou-se um tema central no estudo da governança. Essa preocupação com a integridade pública surgiu justamente em decorrência dos efeitos perversos que resultam de sua falta. É irônico, embora verdadeiro, que a importância da ética só seja percebida quando verificado o mal que a sua ausência acarreta no uso dos recursos públicos. O seu mérito é contrafactual, assim como costumamos dizer sobre os entes queridos, cujo valor só é dado após a perda. Se cogitamos uma sociedade sem valores éticos, então devemos entender de maneira clara, sem qualquer tipo de preconceito, o que nos espera: podemos retornar ao estado selvagem. 
O Brasil é testemunha dessa tendência. Por aqui, os programas de integridade só ganharam destaque recentemente, sobretudo em decorrência do desvelamento crescente de episódios que expuseram a pobreza moral com que atuam os agentes públicos no desempenho de suas funções, e de como interagem com o setor privado. A lei anticorrupção (Lei n. 12.846/2013), estabelecendo alguns instrumentos de promoção da ética nas empresas, é um exemplo dessa nova preocupação.

Não obstante isso, qualquer medida que vise fortalecer a governança, a institucionalidade, ou que objetive endurecer punições contra a corrupção, será insuficiente se não levar em consideração, primeiro, que os indivíduos guiam as suas condutas por valores construídos ao longo do tempo. Daí a essencialidade de definir uma política dirigida ao revigoramento desses valores, como um componente fundamental para a prevenção de fraudes e a plena realização do direito à boa administração.

Se vivemos ou não em um Estado de Direito consolidado não é algo que dependa exclusivamente da configuração institucional do sistema (se dispõe de leis rigorosas; regulamentação exaustiva de condutas; mecanismos de defesa, monitoramento e punição), mas também, e principalmente, da riqueza de caráter que possuem os agentes públicos e os cidadãos. A virtude compartilhada entre governantes e governados é determinante no crescimento ético da nação. Não chega a ser surpreendente, portanto, a existência de estudos a demonstrar que medidas que incrementem a integridade conduzem à diminuição da corrupção e, paralelamente, ao desenvolvimento econômico. ${ }^{126}$

Lançar-nos-emos aqui ao desafio de encontrar modos de cultivar essa virtude cívica, demonstrando a existência e possível aplicação prática de um conjunto de ações, políticas e mecanismos, nos marcos da ética pública, para servir como dique ao mar da corrupção, frente aos numerosos setores que hoje estão contaminados por este mal. Devemos, para tanto, fugir de atalhos que não nos levarão a lugar algum. Ao invés disso, é melhor que façamos uma autocrítica, reconhecendo que perdemos a rota, para então voltarmos ao caminho certo, ainda que seja mais longo e penoso.

Em geral, na linha do que foi dito no capítulo anterior, a experiência brasileira demonstra uma insistência em combater esse fenômeno pelos seus sintomas externos, partindo de uma visão monocular de produção legislativa, regulamentação e punição. Assim, pouca - ou quase nenhuma - atenção dá-se à parte interna, das

126 MOILANEN, Timo; SALMINEN, Ari. Comparative study on the public service ethics of the EU member states. Helsinki, Ministry of Finance. Research and Studies, 2007, p. 53. 
percepções, convicções e valores. É preciso sedimentar a ideia de que a não aceitação de propina deve ser por convicção, e não por coerção. Que a consciência social dependa unicamente do medo da punição, deve-se presumir que os agentes sancionadores são incorruptíveis, e sabemos que não são. Quando se revigoram os valores de honestidade e decência, estes fortalecem, motivam e dão integridade à conduta do indivíduo.

Essa visão ganha contornos ainda mais relevantes quando se verifica que a própria definição de corrupção, atualmente, inclui condutas que, embora não sejam ilícitas no estrito sentido de violarem uma regra preestabelecida, são imorais ou desvirtuadas, a exemplo da elaboração de normas favoráveis a determinados setores industriais, em troca de facilidades futuras. Nesses casos, a busca pelo interesse privado em detrimento do coletivo se dá nos marcos da lei.

O primeiro passo a ser dado por qualquer sociedade imersa na corrupção é querer deixar de sê-lo. Torna-se necessário então materializar esse interesse e disseminá-lo até atingir o amadurecimento de uma cultura de integridade no Brasil, tão acostumado a desvios e dilapidaçôes. Veja: um agricultor que, ao ter a sua safra destruída pela ação de parasitas, replanta o danificado e se limita a comprar o veneno, não age de modo eficaz, já que é provável que a praga se adapte e resista aos efeitos do agrotóxico. Entender o comportamento desses parasitas e, então, adotar as medidas que impeçam o seu desenvolvimento pode apresentar resultados melhores. O mesmo vale para a corrupção: como modelo baseado na obtenção de privilégios pessoais em detrimento do bem público, antes de replantar, é melhor analisarmos as causas e desenvolver bloqueios que inibam comportamentos corruptos.

Devemos dirigir atenção, portanto, à institucionalização de uma estrutura ética, que combine medidas e estratégias dirigidas à prevenção de condutas irregulares no setor público, privado e social, modelando comportamentos que valorizem o respeito à lei e à coisa pública, já que nenhum cidadão consegue viver em uma comunidade corrompida. Trata-se de reverter o círculo vicioso da conformidade social com práticas desonestas, incutindo na percepção pública o gosto pela honestidade.

O principal desafio à construção dessa infraestrutura ética é que, nas atuais sociedades de distanciamento, usando a fórmula de Michael Wazer, os indivíduos confiam cada vez menos na integridade de seus governantes, bem como uns nos outros. Há uma impressão antropológica utilitária generalizada segundo a qual todos os seres humanos são movidos pelo interesse próprio, buscando constantemente a maximização de benefícios.

Especialmente, em relação aos agentes políticos, os índices de confiança são cada vez mais baixos. Embora seja difícil encontrar causas específicas e com apoio 
empírico, acredito que se trata de um problema geral de accountability, em seus dois matizes: pelo lado da responsividade, o declínio da capacidade governamental de responder às demandas sociais crescentes, ensejando um dilema moderno ao Estado brasileiro, que custa aos cidadãos muito mais daquilo que lhes entrega. Do lado da responsabilidade, a pobreza ética com que os eleitos atuam em nome dos cidadãos, refletida nos inúmeros escândalos públicos envolvendo gestores e parlamentares. Apenas para demonstrar como são cambiantes as causas encontradas, Pippa Norris, ao abordar o fenômeno dos cidadãos críticos no século XXI, indica que a desconfiança política é fruto da insatisfação crescente com a performance dos governos democráticos, aliada à cobertura profundamente negativa da mídia sobre as instituições políticas. ${ }^{127}$

Se o governo não diz a verdade, não age com decência, se a sociedade é mal informada e constantemente enganada, então não há motivos para que o povo não retribua na mesma moeda, mentindo, falsificando ou fraudando. Sem confiança mútua e honestidade, só pode haver corrupção mútua e governo ineficaz. ${ }^{128}$

Além disso, quando disseminada na sociedade essa desconfiança, frustração e desencantamento, verifica-se uma expansão de antivalores. Dos prejuízos massivos que advém da corrupção, talvez o mais perigoso seja a deterioração moral dos cidadãos, que passam a desvirtuar valores, menosprezar a ética e enxergar os desvios públicos como algo tolerável, ou pior, normal. Em suma: instituiçóes ineficazes e corrompidas podem levar os cidadãos a comportar-se negligenciando princípios morais, por considerá-los sem importância. Essa combinação condiz com a crença profunda de que determinada pessoa, por mais honesta que seja, uma vez inserta na arena política, certamente tornar-se-á corrupta, o que é sintomático não só de como os indivíduos veem com cinismo o modo de atuar dos agentes públicos, mas também como pensam que realmente há uma proporção maior de pessoas corruptas do que honestas na sociedade. Como na clássica expressão de Edmund Burke: "para que o mal triunfe, basta que os bons não façam nada".

No final de 2016, dois pesquisadores do departamento de Psicologia Social da Universidade Yale conduziram uma série de experimentos a fim de examinar como ocorre o processo de normalização de algo, ou seja, como as pessoas decidem se algo é normal ou não. O que descobriram é ao mesmo tempo surpreendente e assustador: que quando pensam sobre o que é normal, os indivíduos combinam

127 NORRIS, Pippa. Democratic deficit: critical citizens revisited. Cambridge University Press, 2011.

128 ASPET, Daisy de; CAIDEN, Gerald E. A essência do profissionalismo no serviço público. Revista de Informação Legislativa, Brasília, ano 35, n. 138, abr./jun. 1998. 
indistintamente os seus sentidos sobre o que é comum ou típico (descritivo) e o que é certo (prescritivo), e acabam misturando esses conceitos num julgamento indiferenciado de normalidade. Em outras palavras: situações, simplesmente por se tornarem mais comuns, ainda que não sejam morais ou corretas, tornam-se aceitáveis ou toleráveis. Nesse contexto, passamos a categorizar os desvios morais (corrupção, fraude, desperdícios), quando estes são mais recorrentes em nossa realidade, em termos de uma pobre e indiscriminada noção de normalidade. ${ }^{129}$ Nara Pavão descreve os efeitos que esta exposição crescente das pessoas aos escândalos públicos exerce no processo eletivo. Segundo ela, a percepção ampla, por parte dos eleitores, de que o desvio é banalizado entre os potenciais candidatos, faz com que a corrupção deixe de representar um critério de escolha na hora da eleição, vez que percebida como algo normal. ${ }^{130}$

O que se busca alcançar através da institucionalização da ética é obstruir a tentação de passividade que tende a enquadrar atos abusivos como inofensivos, e passa a aceitar o inaceitável. $\mathrm{O}$ rei está inteiramente nu e seguimos elogiando o bom gosto de seu alfaiate. Pergunta-se: de que importa um singelo ato honesto neste contexto de corrupção generalizada? Mas essa solução só será possível se os atores confiarem em si mesmos, e em quem governam as instituições que servem ao interesse público. Ao existir confiança, é natural que se gere harmonia, participação, interação, transparência e cooperação entre governantes e governados. A isto se denomina boa governança. Por isso decidi falar do aspecto ético em primeiro lugar.

A soma das medidas de institucionalização da decência integra o que chamarei de sistema ético integral, ${ }^{131}$ aonde se ajustam elementos que, encarados como uma verdadeira infraestrutura ética, servirão ao controle preventivo. Dividi a abordagem desde uma perspectiva de proporção: primeiro, falarei sobre o papel dos

129 BEAR, Adam; Knobe, Joshua. Normality: part descriptive, part prescriptive. Cognition, Elsevier, 2016.

130 PAVÃO, Nara. The failures of electoral accountability for corruption: Brazil and beyond. Graduate Program in Political Science. Notre Dame, 2015.

131 Esse sistema: "fortalece e reivindica a dignidade dos profissionais do serviço; desperta o espírito de cooperação, comunicação e coesão de grupo; eleva a moral e fomenta a motivação; cria disposição para a resolução de conflitos; fortalece a consciência sobre a divisão entre o público e o privado; forma pessoas eficazes em suas tarefas; forma pessoas que exercitam o autocontrole; incorporam e fortalece princípios e valores; aclara os pensamentos ante situações de dúvidas e dilemas; e reitera os fins do Estado mediante o espírito de serviço público". BAUTISTA, Óscar Diego. Ética para corruptos: una forma de prevenir la corrupción en los gobiernos y administraciones públicas. 2. ed. Descleé de Brouwer, 2009, p. 17. 
- Finanças públicas: travessia entre o passado e o futuro

líderes éticos, que fornecem bons exemplos de integridade à sociedade, influenciando comportamentos e percepções. Noutra perspectiva, falarei da ética corporativa, materializada através do compliance, termo alçado à fama no Brasil e no mundo. Por fim, me ocuparei da ética pública, ressaltando a possibilidade de aplicação dos programas de integridade no setor público e a importância da reforma política por meio da educação cívica. Após, partirei para a ética individual, manifestada por aqueles que, a despeito das inúmeras dificuldades, decidem se levantar contra a corrupção (whistleblowers).

Se enganam aqueles que colocam esses temas em lugar remoto na ordem de prioridades no controle. A ética é a outra face da moeda da corrupção, e para não ficar estagnada no plano do discurso (como acontece com a maioria dos poucos instrumentos de integridade no Brasil), precisa de instrumentos, programas e ações. Quem sabe em um futuro não distante poderemos dizer que a honestidade compensa. 